\title{
MODEL PEMBELAJARAN IPA DENGAN ALAT PERAGA SEDERHANA UNTUK MENINGKATKAN PEMAHAMAN DAN KREATIVITAS SISWA DI MTS MA'ARIF CIKERUH, JATINANGOR
}

\author{
Budiman, A., Inggriani, A.S., Prasetyo, Y.A. Fauziah, N. dan Septiana, N. \\ Program Studi Sarjana Farmasi, Fakultas Farmasi, Universitas Padjadjaran \\ E-mail: arifbudimanapt@gmail.com
}

\begin{abstract}
ABSTRAK
Praktikum merupakan strategi pengajaran yang digunakan untuk menggambarkan materi pembelajaran. Alat peraga merupakan salah satu alat praktikum yang diperlukan untuk membantu dalam kegiatan pembelajaran. Tujuan dari kegiatan ini adalah untuk membuat alat peraga dalam upaya peningkatan pemahaman dan kreativitas pelajar pada mata pelajaran IPA di MTs Ma'arif Cikeruh, Jatinangor. Kegiatan diawali sosialiasi ke MTs Ma'arif Cikeruh Jatinangor dilanjutkan dengan persiapan alat-alat dan bahan yang akan digunakan, kemudian dilakukan percobaan pemasangan alat sebelum didemonstrasikan kepada siswa. Sebelum membuat alat peraga, siswa diberikan pre-test dan penjelasan teori yang berkaitan dengan alat peraga yang dibuat.Alat-alat peraga yang dibuat meliputi auksanometer sederhana, bioreaktor sederhana, alat distilasi sederhana, alat fermentasi sederhana, miniatur pompa hidrolik, penyaring air sederhana, indikator asam basa alami, air mancur berwarna, dan sugar snake. Pelaksanaan kegiatan berlangsung dua minggu sekali selama 4 bulan dari Bulan Maret hingga Juni 2016 dan akan berkelanjutan terkait dengan evaluasi dan monitoring kegiatan. Evaluasi dan monitoring meliputi aspek afektif, psikomotorik, dan kognitif. Penilaian aspek afektif dan psikomotorik meunjukkan kriteria sangat baik, sedangkan untuk aspek kognitif siswa dilakukan dengan pre-test dan post-test setiap pertemuan. Nilai rata-rata dari hasil pre-test yaitu 40,75, setelah praktikum dilaksanakan post-test dengan nilai rata-rata yaitu 74,125. Sehingga disimpulkan kegiatan praktikum meningkatkan pemahaman siswa sebesar 33,375.
\end{abstract}

Kata kunci: alat peraga sederhana, IPA, siswa SMP

\section{ABSTRACT}

Practicum is a teaching strategy that is used to describe the learning materials. Props is one of the practical tools needed to assist in the learning activities. The purpose of this activity is to create props in enhancing the understanding and creativity of students in science subjects in MTs Ma'arif Cikeruh, Jatinangor. The event begins socialization to MTS Ma'arif Cikeruh Jatinangor, followed by the preparation of tools and materials to be used, then conducted the experiment installation of equipment before it is demonstrated to the students. Before making props, students are given a pre-test and explanation of theories related to props are made. Props are made include simple auksanometer, simple bioreactor, simple distillation apparatus, means of fermentation, miniature hydraulic pump, a water filter is simple, natural ph indicator, colored fountains, and sugar snake. Implementation of the activities take place every two weeks for four months from March to June 2016 and will be associated with the ongoing evaluation and monitoring activities. Evaluation and monitoring includes affective, psychomotor, and cognitive. Rate affective and psychomotor aspects conveniently indicates the criteria very well, while the students do with the cognitive aspects of the pre-test and post-test each meeting. The average value of the pre-test is 40.75, after a practicum conducted post-test with the average value is 74.125 . Thus concluded practicum enhance students' understanding of 33.375.

Key words: simple props, science, junior high school students

\section{PENDAHULUAN}

Departemen Pendidikan dan Kebudayaan (2007) menyatakan bahwa fungsi pembelajaran Ilmu Pengetahuan Alam (IPA) adalah mengembangkan wawasan, sikap, dan nilai yang berguna bagi siswa untuk meningkatkan kualitas kehidupan sehari-hari. Samatowa (2011) menyatakan bahwa IPA memiliki faedah bagi suatu bangsa, sebab IPA merupakan dasar teknologi dan disebut-sebut sebagai tulang punggung pembangunan. Sehingga, pembelajaran IPA dapat dijadikan sebagai wahana dalam meningkatkan kualitas SDM.

Pembelajaran IPA yang baik harus mengaitkan IPA dengan kehidupan sehari-hari siswa. Siswa diberi kesempatan untuk mengajukan pertanyaan, membangkitkan ide-ide, membangun rasa ingin tahu tentang segala sesuatu yang ada di lingkungannya, membangun keterampilan yang diperlukan, dan menimbulkan kesadaran bahwa belajar IPA menjadi sangat diperlukan untuk dipelajari. Penggunaan media pembelajaran akan memperbanyak pengalaman belajar siswa, membuat siswa menjadi tidak bosan, dan memberikan pembelajaran yang menarik kepada siswa (De Vito dalam Samatowa, 2011). 
Untuk mengubah pemikiran dan pengetahuan yang dimiliki siswa menjadi konsep ilmiah perlu diupayakan strategi konflik kognitif (Mariawan, 1997). Konflik kognitif merupakan tujuan utama dari pembelajaran perubahan konseptual yang diciptakan agar siswa tidak puas dengan konsep awal yang bersifat umum yang dimiliki dan kemudian menerima pandangan normatif yang masuk akal dan bermanfaat (Ozdemr and Clark, 2007). Jadi, strategi konflik kognitif merupakan strategi yang tepat untuk mengubah konsep alternatif siswa menjadi konsep ilmiah. Selain itu, fenomena kegagalan dalam pencapaian tujuan esensial pendidikan IPA disebabkan karena dalam pembelajaran IPA tersebut hanya bersifat sebagai suatu aktivitas pemberian informasi yang diterima begitu saja dan kurang memanfaatkan alat peraga sebagai sumber belajar. Menurut Sanjaya (2006) dalam proses pembelajaran, siswa kurang didorong untuk mengembangkan kemampuan berpikir. Proses pembelajaran di dalam kelas diarahkan kepada kemampuan untuk menghafal informasi tanpa dituntut untuk memahami informasi yang diingatnya dan menghubungkannya dengan kehidupan sehari-hari.

Untuk menyampaikan pesan belajar dibutuhkan sebuah media pembelajaran agar pembelajaran yang berlangsung menjadi mudah dan menyenangkan bagi siswa. Jika media didesain dan dikembangkan secara baik, maka fungsi dapat diperankan oleh media meskipun tanpa keberadaan guru. Untuk itu penggunaan media pembelajaran sangat membantu guru dalam proses pembelajaran tetapi harus diperhatikan oleh guru sebelum menerapkannya dalam kelas. Salah satu media pembelajaran yang dapat digunakan dalam pembelajaran IPA adalah alat peraga. Roestiyah (1986) menyatakan media pendidikan adalah alat metode dan teknik yang digunakan untuk meningkatkan efektivitas komunikasi dan interaksi edukatif antara guru dan siswa dalam proses pendidikan dan pengajaran di sekolah. Lebih lanjut menurut Natawidjaja (1978), alat peraga yaitu alat pelengkap yang digumakan guru dalam berkomunikasi dengan para siswa. Alat peraga diartikan sebagai segala sesuatu yang dapat di digunakan untuk menyalurkan pesan, merangsang pikiran, perasaan, perhatian dan kemauan siswa sehingga dapat mendorong proses belajar (Ali, 1992). Menurut Sudjana (2009), dalam proses belajar mengajar alat peraga dipergunakan dengan tujuan agar proses belajar siswa lebih efektif dan efisien. Pembelajaran menggunakan alat peraga berarti mengoptimalkan fungsi seluruh panca indra siswa untuk meningkatkan efektivitas siswa belajar dengan cara mendengar, melihat, meraba, dan menggunakan pikirannya secara logis dan realistis. Tidak semua media pembelajaran disebut sebagai alat peraga, akan tetapi semua alat peraga pasti merupakan media pembelajaran. Sehingga keduanya berfungsi memudahkan peserta didik dalam memahami materi pelajaran. Alat peraga digunakan untuk melatih keterampilan proses seperti mengamati, bertanya, merumuskan masalah dan hipotesis, interpretasi data, menarik kesimpulan, dan berkomunikasi dalam bentuk praktikum (Nur, 2011). Keterampilan proses perlu dikembangkan dalam pembelajaran dikarenakan siswa akan mampu menemukan dan mengembangkan sendiri fakta dan konsep serta menumbuhkan sikap dan nilai.

Hasil belajar IPA siswa akan optimal jika guru berpikir cermat dalam mendesain pembelajaran yang dapat memberdayakan siswa dan akan lebih mengoptimalkan penggunaan alat peraga dalam pembelajaran IPA. Jika tujuan pembelajaran mengarahkan siswa untuk suatu bentuk pemahaman, guru harus memiliki gagasan tentang bagaimana siswa berpikir. Oleh karena itu, para guru harus mencoba untuk memperkirakan dari apa yang dapat diamati dari siswanya, apa konsep siswa tersebut, dan bagaimana para siswa menggunakan konsep tersebut. Karena dengan cara itu, guru dapat mengatur cara-cara dan alat orientasi, mengarahkan atau mengubah cara kerja mental siswa.

Studi pendahuluan melalui observasi langsung pada saat proses pembelajaran yang dilakukan peneliti di kelas VIII MTs Ma'arif Cikeruh, Jatinangor. Pada observasi tersebut dapat dilihat bahwa pembelajaran yang diterapkan masih menggunakan metode ceramah. Menurut wawancara dengan guru mata pelajaran IPA, siswa hanya diberikan materi saja tanpa diberikan praktikum pada saat pelajaran. Kegiatan praktikum akan diberikan apabila waktu dan alat praktikum tersedia. Karena jarang melakukan praktikum, siswa memiliki keterampilan proses yang masih kurang. Kemudian untuk praktikum di sekolah tersebut juga belum memadai. Dengan adanya pengembangan alat peraga ini diharapkan keterampilan proses dan psikomotor siswa dapat terlatih.

\section{METODE}

Penelitian ini merupakan penelitian pengembangan dengan menggunakan metode 4-D (four D model) yang dikembangkan oleh Thiagarajan (1974). Tahap tersebut antara lain: define (pendefinisian) yaitu menemukan masalah yang ada di sekolah kemudian mencari penyelesaian dari masalah tersebut, design (perencanaan) yaitu merencanakan alat yang telah menjadi solusi dari permasalahan, develop (pengembangan) merupakan langkah pengembangan alat, kemudian disseminate (penyebaran)

Data-data yang diperoleh untuk memperoleh kelayakan alat menggunakan lembar validasi. Kemudian 
untuk aktivitas siswa selama pembelajaran digunakan lembar observasi. Evaluasi keterlaksanaan pembelajaran didukung dengan penilaian afektif, penilaian psikomotor, dan penilaian kognitif. Sedangkan data yang diperoleh dari angket respon siswa terhadap pembelajaran yang dilakukan dan dianalisis menggunakan persentase respon siswa.

\section{HASIL DAN PEMBAHASAN}

Pada pelaksanaan kegiatan praktikum ini mengikuti metode 4D, yaitu 4 tahapan yang meliputi define (pendefinisian) yaitu menemukan masalah, kegiatan ini dilatar belakangi kondisi MTs Ma'arif yang berada di dekat Universitas Padjadjaran dengan kondisi sekolah yang kurang memadai dari aspek peralatan penunjang pendidikan, salah satunya alat peraga praktikum. Sehingga kegiatan difokuskan pada pembuatan alat peraga sederhana pada mata pelajaran IPA. Tahap kedua yaitu design (perencanaan), pada tahapan ini dilakukan perencanaan terkait modul praktikum yang akan dilaksanakan, dilihat dari aspek ekonomi dan fungsional yang sesuai dengan tingkat SMP atau sederajat. Tahap ketiga yaitu develop (pengembangan), pada tahap ini dibuat alat peraga berdasarkan modul yang telah direncanakan sebelumnya, selain itu dilakukan uji coba (trial) terkait alat peraga yang telah direncanakan. Selanjutnya pada tahap keempat yaitu disseminate (penyebaran), yaitu dilakukan kegiatan sosialisasi dan kegiatan pelatihan atau praktikum kepada siswa-siswi di MTs Ma'arif Cikeruh, Jatinangor terkait alat peraga sederhana mata pelajaran IPA.

Analisis hasil penilaian aktivitas siswa terbagi menjadi dua, yaitu penilaian afektif dan penilaian psikomotor. Penilaian afektif siswa dilakukan untuk mengetahui sejauh mana siswa mampu menunjukkan sifat dan karakter pada saat kegiatan praktikum berlangsung. Penilaian afektif siswa terdiri dari lima aspek, yaitu partisipasi siswa, perhatian siswa ketika dijelaskan, kedisiplinan siswa, ketepatan waktu dalam menyelesaikan percobaan, dan kemampuan memperoleh data. Nilai rata-rata afektif secara klasikal untuk kelompok 1 adalah 80,06; kelompok 2 adalah 80,12; dan kelompok 3 adalah 80,22. Nilai rata-rata klasikal tertinggi dicapai oleh kelompok 3 yaitu sebesar 80,22. Hal ini dikarenakan minat belajar siswa yang tinggi sehingga sebagian besar siswa aktif dalam kegiatan pembelajaran seperti dengan mengajukan pertanyaan, mencatat setiap hasil percobaan, dan menyelesaikan praktikum dengan baik. Berdasarkan data nilai afektif rata-rata maka didapatkan grafik batang sebagai berikut:

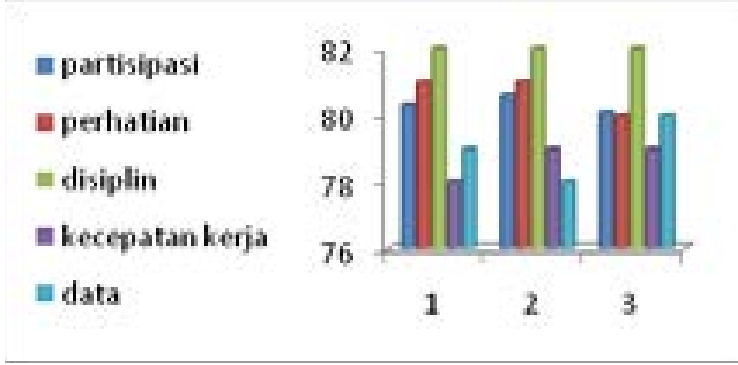

Gambar 1. Grafik batang nilai afektif siswa

Penilaian psikomotor siswa dilakukan untuk mengetahui kemampuan dan kesiapan siswa pada saat praktikum berlangsung. Penilaian psikomotor siswa terdiri dari lima aspek, yaitu merangkai alat dengan benar, rapi dan memperhatikan keselamatan kerja, pengamatan dilakukan dengan cermat tanpa adanya manipulasi data, data yang diperoleh lengkap, terorganisir dan ditulis dengan benar, kerja sama antar kelompok selama percobaan berlangsung, dan kesimpulan. Nilai rata-rata psikomotor secara klasikal untuk kelompok 1 adalah 80,32; kelompok 2 adalah 80,5; dan kelompok 3 adalah 80,1 . Nilai rata-rata klasikal tertinggi dicapai oleh kelompok 2 yaitu sebesar 80,5. Dari data penilaian psikomotor tersebut dapat disimpulkan bahwa kelompok 2 memiliki kemampuan psikomotor dibandiing dengan kelompok lain, terdapat beberapa siswa dalam kelompok tersebut memiliki kemampuan psikomotor yang lebih dibanding siswa lain. Berdasarkan data nilai psikomotor rata-rata maka didapatkan grafik batang sebagai berikut:

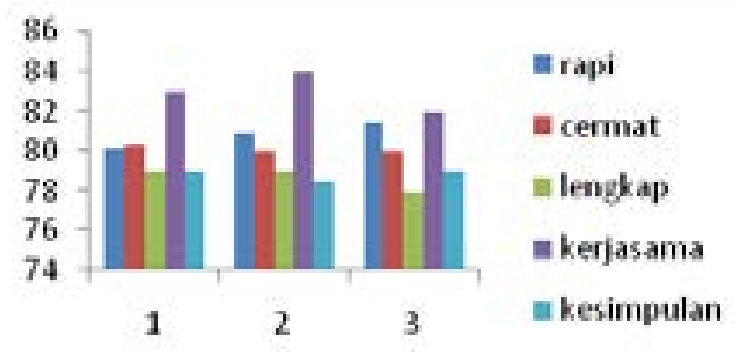

Gambar 2. Grafik batang nilai psikomotorik siswa

\section{Hasil Observasi Pemahaman Siswa}

Hasil observasi pemahaman siswa sebagai aspek kognitif dilakukan dengan pre-test dan post-test untuk masing-masing modul. Sehingga dapat dilihat pengaruh penggunaan alat peraga terhadap tingkat pemahaman dan kreativitas siswa di MTs Ma' arifCikeruh, Jatinangor.

Berdasarkan hasil dari kegiatan pembuatan alat peraga sederhana diperoleh data tingkat pemahaman siswa didasarkan dari nilai pre-test dan post-test dari siswa kelas 8 MTs Ma'arif Cikeruh, Jatinangor. Data tersebut diperoleh dari nilai yang diperoleh dari perwakilan kelas $8 \mathrm{~A}, 8 \mathrm{~B}, 8 \mathrm{C}, 8 \mathrm{D}, 8 \mathrm{E}, 8 \mathrm{~F}$, dan $8 \mathrm{G}$ masing-masing 6 orang setiap kelas. 
Tabel 1 Presentase hasil observasi pemahaman siswa

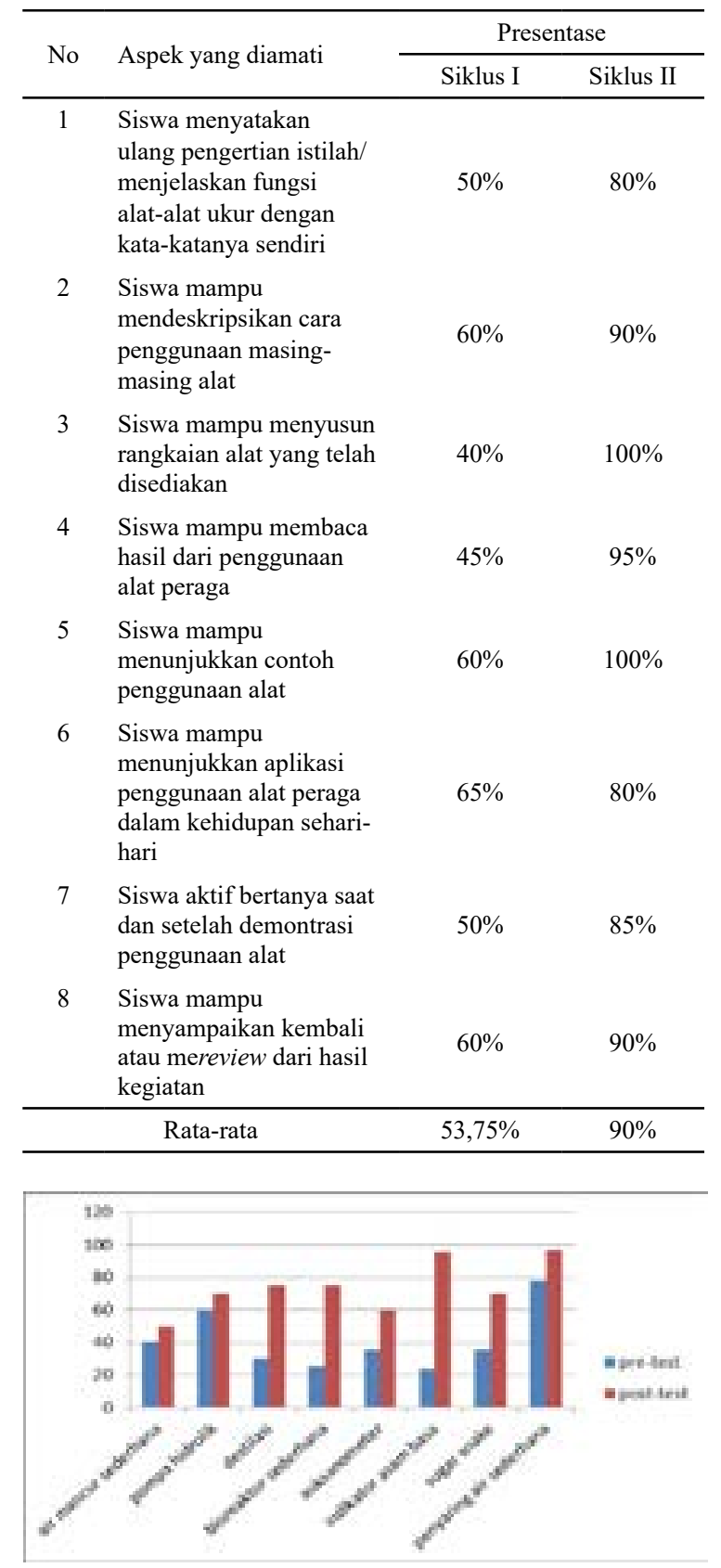

Gambar 3. Grafik batang mengenai nilai pre-test dan post-test dari siswa kelas 8 MTs Ma'arifCikeruh, Jatinangor untuk setiap materi

Dari grafik tersebut dapat disimpulkan bahwa pemahaman siswa mengenai materi praktikum meningkat setelah kegiatan praktikum. Dapat dilihat dari kenaikan nilai yang signifikan untuk setiap materinya.Disamping itu, antusiasme dan sikap kritis siswa juga meningkat, dilihat dari aktivitas selama kegiatan berlangsung, baik yang ingin menjadi relawan untuk demo di depan kelas, maupun dari pertanyaan yang diajukan setelah kegiatan dilaksanakan.
Tabel 2. Nilai pre-test dan post-test siswa kelas 8 MTs Ma'arif Cikeruh, Jatinangor untuk setiap materi

\begin{tabular}{clcc}
\hline No. & \multicolumn{1}{c}{ Materi Praktikum } & $\begin{array}{c}\text { Nilai } \\
\text { Pre-Test }\end{array}$ & $\begin{array}{c}\text { Nilai } \\
\text { Post-Test }\end{array}$ \\
\hline 1 & Air mancur sederhana & 40 & 50 \\
2 & Miniatur pompa hidrolik & 60 & 70 \\
3 & Alat destilasi sederhana & 30 & 75 \\
4 & Bioreaktor sederhana & 25 & 75 \\
5 & Auksanometer sederhana & 35 & 60 \\
6 & Indikator asam basa alami & 23.4 & 96 \\
7 & Sugar snake & 35 & 70 \\
8 & Alat penyaring sederhana & 77.6 & 97 \\
\hline
\end{tabular}

\section{SIMPULAN}

Berdasarkan hasil dari kegiatan praktikum dan pembahasan maka dapat disimpulkan bahwa terdapat perbedaan yang signifikan hasil belajar mata pelajaran IPA antara sebelum dan sesudah penggunaan alat peraga sederhana. Penggunaan alat peraga untuk kegiatan praktikum memiliki pengaruh yang terhadap pemahaman dan kreativitas siswa MTs Ma'arif Cikeruh, Jatinangor. Hal tersebut didukung oleh aspek afektif dan psikomotor siswa pada saat kegiatan praktikum berlangsung. Selain kedua aspek tersebut, aspek utama yang diperhatikan yaitu aspek kognitif yaitu nilai rata-rata dari hasil pretest yaitu 40,75, setelah praktikum dilaksanakan post-test dengan nilai rata-rat yaitu 74,125 . Sehingga disimpulkan bahwa kegiatan praktikum meningkatkan pemahaman siswa sebesar 33,375 dilihat dari nilai yang diperoleh.

Saran yang dapat disampaikan berdasarkan hasil kegiatan yang telah dilakukan yaitu perlu adanya dukungan dari pemerintah atau dinas terkait di dalam pemenuhan kebutuhan kegiatan belajar mengajar yaitu berupa alat peraga praktikum, sehingga sekolah dapat melangsungkan kegiatan praktikum dengan baik dan sehingga meningkatkan pemahaman dan kreativitas siswa.

\section{DAFTAR PUSTAKA}

Ali, Muhammad. 1992. Guru Dalam Proses Belajar Mengajar. Bandung : Sinar Baru.

Depdikbud. 2007. Kurikulum Tingkat Satuan Pendidikan. Bandung: Departemen Pendidikan dan Kebudayaan.

Mariawan, I .M. 1997. "Efektivitas Strategi Konflik Kogntif Dalam Pembelajaran Gaya Dan 
Tekanan". Aneka Widya STKIP Singaraja, Nomor 3 (hlm.92-99).

Natawidjaja, R. 1978. Alat Peraga dan Komunikasi Pendidikan. Bandung: Departemen Pendidikan dan Kebudayaan.

Nur, M. 2011. Modul Keterampilan Proses Sains. Surabaya: Universitas Negeri Surabaya Pusat Sains dan Matematika Sekolah (PSMS).

Ozdemr, G. D and D. B. Clark. 2007. “An Overview of Conceptual Change Theories". Eurasia Journal of Mathematics, Science \& Technology

Education, Volume 3, Nomor 4 (hlm.351-361).
Roestiyah. 1986. Masalah-masalah Ilmu Keguruan. Jakarta: Bina Aksara.

Samatowa, U. 2007. Pembelajaran IPA di

Sekolah Dasar. Jakarta: Universitas Terbuka.

Sanjaya, W. 2006. Strategi Pembelajaran Berorientasi Standar Proses Pendidikan. Jakarta: Prenada Media Group.

Thiagarajan, S., Semmel, D.S., and Semmel, M.I. 1974. Instructional Development for Training Teachers of Expectional Children. Minneapolis, Minnesota: Leadership Training Institute/Special Education, University of Minnesota. 